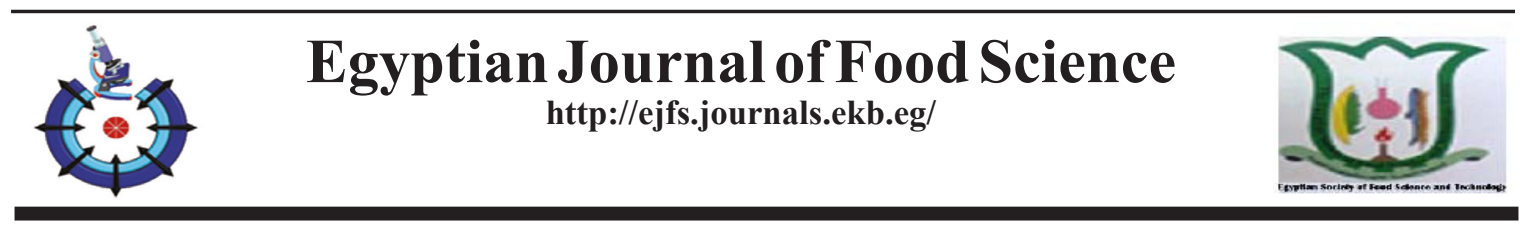

\title{
Utilization of Olive Pomace As A Source of Bioactive Compounds in Quality Improving of Toast Bread
}

\author{
Khaled A. Sleim ${ }^{1 *}$, Waleed Z. Badawy ${ }^{2}$ and I. Smetanska ${ }^{3}$ \\ ${ }^{1}$ Food science and technology Department, Faculty of Agriculture, Fayoum University, \\ Egypt \\ ${ }^{2}$ Food Technology Department, Faculty of Agriculture, Kaferelsheikh University, \\ Egypt \\ ${ }^{3}$ Department of Plant Food Processing, Agricultural Faculty, University of Applied \\ Science Weihenstephan-Triesdorf, Weidenbach, Germany
}

\begin{abstract}
$\mathbf{O}$ LIVE oil pomace is produced as by-product with a large quantity during olive oil processing. It is a promising source for polyphenolic compounds and fibers which could be used in food industry. In this work proximate chemical analysis of olive pomace (two-phase olive oil extraction) was studied. Also, seven extracting solvents were tested in extracting the phenolic compounds from the olive pomace (OP). Total phenolic, flavonoids, and flavonols contents of the different extracts were determined. In addition to, the antioxidant activity of the phenolic extracts was investigated using 2, 2-diphenyl-1-picrihydrazyl (DPPH) to assess the extracting efficiency of solvents. The obtained data rivaled that protein, fat, ash and fiber contents of OP were 2.48, 2.33, 1.33 and $20.37 \%$ (FW), respectively. It is clear that the OP contains a large quantity of fibers and it had cellulose content about $40.7 \%$ of the fiber content. Furthermore, the total phenolic content was varied in the various extracts and ranged from 8.29 to $36.24 \mathrm{mg} \mathrm{GAE} \mathrm{g}^{-1}$. While, total flavonoids were ranged from 2.23 to $12.52 \mathrm{mg} \mathrm{QE} \mathrm{g}^{-1}$. Methanol and water (80:20) recorded the highest antioxidant activity with $\mathrm{EC}_{50}$ of $1.373 \mu \mathrm{g} / \mu \mathrm{g}$ $\mathrm{DPPH}$ while, the acetone extract recorded the lowest antioxidant activity with $\mathrm{EC}_{50}$ of $8.052 \mu \mathrm{g}$ $/ \mu \mathrm{g}$ DPPH. Toast bread was fortified with the cellulose isolated from OP at three replacement levels of 2,4 , and $6 \%$ and the results showed no significant differences between control sample and the sample fortified with $2 \%$ cellulose in most of sensory characteristics tested. Addition of pomace cellulose at replacement level of $2 \%$ enhanced the texture of the bead and was more acceptable than the control. The results concluded that olive pomace is a good source for dietary fibers and polyphenolic compound which could be used in the food industry.
\end{abstract}

Keywords: Olive pomace, Bioactive compounds and Toast bread.

\section{Introduction}

Olive oil showed very interested nutritional and sensorial properties due to its contents of unsaturated fatty acids and polyphenolic compounds which act as natural antioxidants to protect human body (Paz Aguilera et al., 2005). In addition to antioxidant activity of olive phenolic compounds, it was found to have antifungal activity (Winkelhausen et al., 2005). Extraction process of the olive oil production generates a considerable quantity of by-products which could cause serious environmental problems due to its very high organic loads (Roig et al., 2006). Those by-products found to consist of sugars, pectin, lipid, tannins and polyphenolic compounds. Utilization of it as a raw material for producing a high value compounds is particularly attractive way to reuse it (Niaomakis and Halvadakis, 2004).

Three different kinds of by-products are produced during the olive oil production depending on the production method used. (Fenandyez-Bolanos et al., 2006). The traditional

*Corresponding author email: kas00@fayoum.edu.eg.

Received:22/1/2020; accepted:27/2/2020

DOI: $10.21608 /$ EJFS.2020.22871.1038

(C2020 National Information and Documentation Centre (NIDOC) 
press method generates three phase and two byproducts: olive oil about $(20 \%)$, solid by-product (olive cake) around $(30 \%)$ and waste water about $(50 \%)$ of the olive fruits (Jerman Klen and Mozetic Vodopivec, 2012). On the other hand, the two-phase extraction system generates olive oil and one by-product which is a combination of liquid and solid. This by-product contains about $80 \%$ of the olive fruit which include pulp, skin, seeds and pieces of stones (Vlyssides et al., 2004). The by-product in this production method (olive pomace) differs in its chemical properties compared to olive cake from the traditional three-phase extraction method. It has higher moisture content ranged from $65-75 \%$ compared to $22-25 \%$ for the olive cake (Alburquerque et al., 2004). OP is the major output from the twophase extraction method it is a good source for bioactive compounds which could be used in food manufacturing as well as pharmaceutical fields. Because of the high-water content of olive pomace, the concentration of water soluble salts and phenolic compounds in it were higher than that of the olive cake produced by the three-phase extraction system (Dermeche et al., 2013). Those bioactive compounds could have new application in foods and cosmetic industries (Rodrigues et al., 2017).

The quantity of olive pomace generated during production of olive oil is ranged from 2.75 to 4 tons for each ton of oil depending on fruit quality, and extraction technology (Rorja et al., 2006 and Conterno et al., 2017). OP was found to have a considerable amount of polyphenoilc compound. It was reported that about $89 \%$ of olive fruit phenolic compounds remains in olive pomace for which the functional properties of olive oil and olive pomace are related (Ghanbari et al., 2012). Olive pomace phenolic profile has been studied and found to be fared according to many factors including, fruit ripening, climatic condition, cultivar, origin, and the extraction system (Obied et al., 2008). Some authors found oleuropein and oleuropein derivatives as major compounds (Cioffi et al., 2010). Other researchers reported different major compounds, namely hydroxytyrosol as the main phenolic compounds in olive pomace. (Alu'datt et al., 2010; RubioSenen et al., 2012 and Nunes et al., 2018). The major components in the olive pomace are dietary fiber (including cellulose, hemicellulose, lignin and pectin), protein, lipids, pigment, and polyphenolic compounds (Di Gioia et al., 2002). The inclusions of fibre in the food's formulation will inevitably bring about certain changes to the product. Utilization of OP to obtain natural ingredients like phenolic compounds and dietary fibers to develop new food products is a proms subject (Nunes et al., 2018).

Cellulose is insoluble in cold or hot water and in hot dilute acids or alkalis. (Singanuson et al., 2014). Powdered cellulose used in many food applications, essentially in functional bread, to increase fibre content and to decrease nutritional value of the bread. Addition of cellulose to the bread formulation, results in many changes in the quality properties of the bread (Poran et al., 2008). It is increasing the viscosity of the liquid mixture of flour because its insolubility in water. This leads to form a stronger gas holding structure. Thus, the air bubbles will remain in small sizes and will not float on the surface of the liquid, which results in the product having accurate air bubbles, larger foam size and better stability (Wongsonsarim et al., 2001).. cellulose powder was announced to use as a bulking agent in drink products, meat products, salads, and especially baked and cereal products.

In this current work, various extracting solvents were tested for extracting the phenolic compounds from tow-phase extraction olive pomace. Total phenolic, flavonoids, flavonols contents were also determined and identified using HPLC/DAD- MS. The antioxidant activity of the different phenolic extracts was investigated using DPPH method. Cellulose was isolated from the OP as functional food ingredient and used at different concentrations in toast bread formulation to investigate its effects in the quality proprieties of the produced toast.

\section{$\underline{\text { Materials and Methods }}$}

\section{Materials and reagents}

Olive pomace $(4 \mathrm{~kg})$ from tow-phase extraction olive oil unit was acquired from olive production factory in Fayoum, Egypt. The sample was homogenized and stored at $-20^{\circ} \mathrm{C}$ until analysis. All chemicals used were analytical grade and purchased from sigma-Aldrich, Berlin, Germany

\section{Proximate chemical analysis}

Moisture content was determined using oven at $50^{\circ} \mathrm{C}$ under vacuum for $48 \mathrm{hr}$ and the dried sample was ground to fine powder for using in farther analysis. Fat, total protein, ash, and fiber of OP and toast bread were determined according to (AOAC, 2012). Total protein content was calculated using 6.25 as the nitrogen conversion factor (Nunes et al., 2018). Available carbohydrates were calculated by difference. 
Extraction of phenolic compounds from olive pomace

The dried Olive pomace was first extracted which $n$-hexane in at ratio $(1: 4 \mathrm{~W} / \mathrm{V})$ three times successively to remove the residuals of fats and pigments. Then, the polyphenols were extracted from the OP using varies extracting solvents including acetone, ethanol, ethanol and water (50:50), methanol, methanol and water (80:20), ethyl acetate, and water at solvent to pomace ratio (10: 1). The extraction process was cured out in a shaker at room temperature for $24 \mathrm{hr}$ followed by filtration. The residues were re-extracted under the seam conditions. The total extracts were filtered $(0.45 \mu \mathrm{m})$ and the solvents were evaporated at $35^{\circ} \mathrm{C}$. in a Speed Vacuum Concentrator, SPD $111 \mathrm{~V}$ 230 (Thermo scientific, USA). The yield was calculated and stored in dark at $-20{ }^{\circ} \mathrm{C}$ until used (Alu'datt et al., 2010).

\section{Determination of total phenolic content}

Total phenolic content of the extracts was determined spectro-photometrcally with FolinCiocalteu assay (Vergani et al., 2014). A $20 \mu \mathrm{L}$ aliquot of extracts solutions were mixed with 100 $\mu \mathrm{L}$ of Folin-Ciocalteu's reagent followed by 1.586 $\mathrm{mL}$ of distilled water and followed by $300 \mu \mathrm{L}$ of $20 \% \mathrm{Na}_{2} \mathrm{CO}_{3}$ solution. The obtained mixtures were incubated in a shaking incubator at $40{ }^{\circ} \mathrm{C}$ for $30 \mathrm{~min}$ and the absorbance was measured at $765 \mathrm{~nm}$. The results were expressed as $\mathrm{mg}$ gallic acid equivalent (GAE) using the following liner equation based on gallic acid calibration curve.

$$
\mathrm{Y}=0.0248 \mathrm{x}+0.237\left(\mathrm{R}^{2}=0.997\right)
$$

Where $\mathrm{A}$ is the absorbance and $\mathrm{C}$ is the concentration (mg GAE g-1 dry weight (DW))

\section{Determination of total flavonoids and flavonols}

Total flavonoids content was determined as described by Mohdaly et al. (2009). Using $\mathrm{AlCl}_{3}$ ethanolic solution and the absorbance was measured at $420 \mathrm{~nm}$. Total flavonoids content calculated and expressed as quercetin equivalent (QE) using the following equation based on the calibration curve:

$$
\mathrm{Y}=0.0035 \mathrm{x}+0.0258\left(\left(\mathrm{R}^{2}=0.9929\right)\right.
$$

Where $\mathrm{Y}$ is the concentration (mg QE/100 $\mathrm{g}$ extract) and $\mathrm{X}$ is the absorbance and Total flavonols content was determined according to the method described by Kumaran and Joel (2007). 2 $\mathrm{mL}$ of $20 \mathrm{~g} / \mathrm{L}^{-1} \mathrm{AlCl}_{3}$ ethanolic solution and $3 \mathrm{~mL}$ of $50 \mathrm{~g} / \mathrm{L}^{-1}$ sodium acetate solution were added to $2 \mathrm{~mL}$ of extract solution. The absorption was recorded after $2.5 \mathrm{hr}$ at $440 \mathrm{~nm}$. Total flavonols content expressed as QE was calculated using the quercetin calibration curve:

\section{Antioxidant activity of olive pomace extracts}

The antioxidant capacity pomace extracts were determined using 2,2-diphenyl-1-picrihydrazyl (DPPH') assay according the method of BrandWilliams et al., (1995) with some modifications. Extracts and synthetic antioxidants (BHA, BHT and TBHQ in ethanol) solutions of different concentrations $(100 \mu \mathrm{L}$ of each) were vortexed for $30 \mathrm{~s}$ with $1.8 \mathrm{~mL}$ of DPPH solution and left to react for $30 \mathrm{~min}$, after which the absorbency of the remaining DPPH was recorded at 515 $\mathrm{nm}$. A control sample was prepared at the same conditions without extract. The measurements were performed in triplicate. Scavenging activity was calculated as follows:

$$
\text { scavenging }(\%)=[(\text { A. control }- \text { A. sample }) / A \text {. }
$$$$
\text { control] } \times 100
$$

Where : A is the absorbance at $515 \mathrm{~nm}$.

Antiradical Efficiency $=1 / \mathrm{EC}_{50}$

$\mathrm{EC}_{50}$ is extraction concentration providing $50 \%$ inhibition of DPPH.

\section{High performance liquid chromatography (HPLC/DAD)}

HPLC was performed in LC10 AD HPLC eluent pump (Shimadzo, Kyoto, Japan), DAD SPDM10 AVP, UV-Vis SPD 10AVP detectors (Shimadzo, Kyoto, Japan). phenolic compounds were separated on a C18 analytical column, 250 $.46 \mathrm{~mm}$ i.d. (Shimadzo, Kyoto, Japan) packed with Luna C18 stationary phase, particle size $3 \mu \mathrm{m}$ and connected to $\mathrm{C} 18$ precolumn. The time of HPLC run was over 40 min. UV-Vis detector was operating at $290 \mathrm{~nm}$ wavelength. Phenolic compounds were identified by comparison of chromatographic retention times and area of the peak in the extract with that of the standard phenolic acids and reference compounds using Mass Lynx 4.0 software (Micromas UR Ltd., UK) and the available literature data (Gheldof et al., 2002).

\section{Determination of cellulose content}

This was achieved by delignification of the sample with chlorous acid followed by elimination of hemicellulose by treatment of the resulting holocellulose with $10 \% \mathrm{NaOH}$ at $80^{\circ} \mathrm{C}$ for 3 hours as reported by Chen et al. (1988) as follows: The lignocelluloses material was first subjected to Soxhlet extraction with a mixture of methanol and benzene (1:1) for $8 \mathrm{hr}$ lignin was then eliminated 
treating 5.0 grams (oven dry) of olive cake with sodium chlorite solution (sodium chloride 1.5 gram in $160 \mathrm{mls}$. of water containing 10 drops of glacial acetic acid). The mixture was left in water bath at $70^{\circ} \mathrm{C}$ for one hour then after, ten drops of glacial acetic acid and 1.5 gram of sodium chlorite were again added and this was repeated twice. After filtration the residual material was washed successively with water and ethyl alcohol to give the holocellulose. For the removal of hemicellulose, the obtained holocellulose was treated $10 \% \mathrm{NaOH}$ solution $(1: 20 \mathrm{~W} / \mathrm{V})$ and heated at $80^{\circ} \mathrm{C}$ in a water bath for $1.5-3.0$ hour. After filtration, the residue was washed with water, ethanol and ether and then dried at $105^{\circ} \mathrm{C}$ to constant weight.

\section{Determination of hemicellulose content}

Hemicellulose content was estimated, gravimetrically, after extraction, as reported by Chen et al. (1988) 10 grams of olive cake with $14 \% \mathrm{NaOH}(100 \mathrm{ml})$ at $90^{\circ} \mathrm{C}$ for $3 \mathrm{hr}$, and precipitated with $\mathrm{HCl}$ at $\mathrm{PH} 5$. The precipitated hemicellulose was separated by centrifugation, washed with ethanol, then dried and weighted.

\section{Determination of lignin content}

Lignin content in the investigated materials was also determined according to the method described by Fahmi (1984) as follows: One gram olive cake extracted using a mixture of methanol and benzene (1:1). In a wide mouthed bottle of $150 \mathrm{ml}$ capacity, $50 \mathrm{ml}$ of $38 \%$ pure HCL (not less than 38\%) was added. The mixture was left for two min, and then $50 \mathrm{ml}$ of concentrated sulfuric acid was added. After shaking for one hour the mixture was left for 24 $\mathrm{hr}$ at $22^{\circ} \mathrm{C}$. The content was poured in a beaker of one-liter capacity. The bottle was washed with $415 \mathrm{ml}$ of distilled water and filtered. The obtained was dried at $105^{\circ} \mathrm{C}$ for $3 \mathrm{hr}$ and weighted.

\section{Cellulose isolation}

The isolation of cellulose was cured out using the methods described by Brendel et al. (2000) as follows: 500 gram of dried olive cake was extracted with aqueous acetic acid $80 \%$ $(\mathrm{w} / \mathrm{w})$ and nitric acid $70 \%(\mathrm{w} / \mathrm{w})$. The residue was then thoroughly washed with distilled water and ethanol $95 \%$ to remove the nitric acid and extraction breakdown products. The residue was then dried in an oven at $60{ }^{\circ} \mathrm{C}$ for $16 \mathrm{hr}$ and was labeled as cellulose.
Determination of dough rheological properties

The effect of powdered cellulose on rheological properties of dough during mixing was determined by the Brabender Farinograph, following the AACC Approved methods (54 - 21, 1983) and the Brabender Extensigraph following the AACC Approved methods (54 10, 1983).

\section{Bread making}

The Straight Dough (Bulk Fermentation) method was used for bread making as described by Pourabedin et al. (2017), the amount of added water was calculated from Table 6 . The control sample was consisted of $100 \mathrm{~g}$ flour, 1.5 $\mathrm{g}$ salt, $1 \mathrm{~g}$ yeast. Three treatments ware prepared with three different replacement levels $0,2,4$ and $6 \%$ of the flour. Dough pieces $(100 \pm 0.1$ g) proofed for 90 minutes at $30{ }^{\circ} \mathrm{C}$ and $90 \%$ relative humidity. Bread was baked at $250^{\circ} \mathrm{C}$ for $25 \mathrm{~min}$.

\section{Sensory evaluation}

Toast bread containing different cellulose powders and control bread were sensory tested in Food Technology Department, Faculty of Agriculture, Kaferelsheikh University, Egypt. For their color, appearance, odor, texture, taste and overall acceptability on a 1 to 10 hedonic scale as described by Meilgaard et al. (2007).

\section{Statistical analysis}

Statistical analysis of the data obtained from the study was performed using the SPSS $\mathrm{v}$ statistical program SPSS v. 16 for windows (SPSS, Chicago, II., USA) The ANOVA method was used to analyze the results. Multiple range tests from Duncan were used at a level of $5 \%$ of significance for comparison of means. All trials were conducted in triplicate.

\section{Results and Discussion}

Proximate chemical composition of olive pomace

The main values obtained for the proximate composition of OP are presented in Table 1. The results showed that the sample presented a moisture content of $64.58 \%(\mathrm{FW})$ and protein content of $2.48 \%$. The data rivaled that ash and fiber content of OP was 1.33 and $20.37 \%$ (FW) respectively. The total lipid of the analysed sample was $2.33 \mathrm{~g} / 100 \mathrm{~g}$ (FW) which could be used in food and cosmetics industry (Rodrigues et al., 2017). Di Giovacchino and Prezioso, (2006) reported that ash content of OP ranged from 1.42 to $4 \%(\mathrm{FW})$. It is clear 
that the OP contains a large quantity of fibers and it had cellulose content about $40.7 \%$ of the fiber content. Several studies have focused on isolation of dietary fibers from olive pomace and reported cellulose, hemicellulos and lignin as the main carbohydrates in olive by-products (Jimenez et al., 1994). In another study, Vlyssides et al., (1998) found that OP contains cellulose, hemicellulos and lignin of $14.54,6.68$, and $8.54 \%$ (DW) respectively. These compounds could be used in many food products as gelling agents, fiber source and fat substitute. It was found that the proximate composition of OP is influences by many factors including ripening stage, cultivar, and agriculture practices (Portarena et al., 2017). Our results agreed with that stated by RosellóSoto et al. (2015) and Nunes et al. (2018).

TABLE 1. chemical composition of olive pomace.

\begin{tabular}{|l|c|}
\hline Olive pomace & $\mathrm{g} / 100 \mathrm{~g}(\mathrm{FW})$ \\
\hline Moisture content & $64.58 \pm 2.51$ \\
\hline Total lipids & $2.33 \pm 0.06$ \\
\hline Protein & $2.48 \pm 0.04$ \\
\hline Ash & $1.13 \pm 0.02$ \\
\hline Total carbohydrates & $29.48 \pm 2.41$ \\
\hline Cud fiber & $20.37 \pm 1.65$ \\
\hline Cellulose* & $40.77 \pm 2.44$ \\
\hline Hemicelluloses* & $33.63 \pm 2.28$ \\
\hline Lignin* & $19.50 \pm 1.79$ \\
\hline
\end{tabular}

*Calculated as a percentage from pomace fiber ( $\%$ on dry weight basis)
Extraction of phenolic compounds from olive pomace by different solvents

The majority of polyphenolic compounds $(98 \%)$ remain in the olive pomace and a small fraction passes into the oil about $(2 \%)$. (Chanioti and Tzia, 2017). To extract the phenolic compounds from OP, suitable solvents must be used according to their extraction efficiency and according to the uses of the compounds to be extracted. The effect of various solvents was assessed to determine the most appropriate one for yield, total phenoilc, flavonoids, and flavonol content of the extracts obtained. Polyphenolic yields were found to increase with increasing the polarity of the solvents. The extract yield was varied from 141.27 to 66.92 g / kg -1 (DW) (Table 2). The obtained results proved that using methanol and water showed highest yield, while acetone scored the minimal polyphenol production (66.92 g / kg DW).

Referring to polyphenols from different extracts, the results showed that the polyphenols content varied from 36.24 to $8.29 \mathrm{mg} / \mathrm{g}^{-1}$. Methanolic extract recorded the highest total polyphenolic content higher than the other solvents While, hand, acetone extract presented the less polyphenolic contents. This because of the high polarity of methanol. The obtained findings similar to those obtained from other researchers who used several solvents to extract phenolic compounds from olive and olive pomac. (Cioffi et al, 2010, Lafka et al, 2011, Vergani et al, 2016, Araújo , 2015 and Albahari et al., 2018). Cedola et al. (2019) found that dry olive paste had phenols content, equal to $45.09 \mathrm{mg} \mathrm{GAE} / \mathrm{g} \mathrm{dw}$, and high amount of flavonoids (36.11 mg QE/g dw).

TABLE 2. The influence of different solvents on yield and total phenolic content of olive pomace.

\begin{tabular}{lcccc}
\hline \multicolumn{1}{c}{ Solvents } & $\begin{array}{c}\text { Extract yield (g/ } \\
\left.\mathbf{k g}^{-1} \mathbf{~ D W}\right)\end{array}$ & $\begin{array}{c}\text { Total phenolic } \\
\left(\mathbf{m g ~ G A E ~} \mathbf{~}^{-1} \mathbf{~ D W}\right)\end{array}$ & $\begin{array}{c}\mathbf{E C}_{\mathbf{5 0}} \\
\boldsymbol{\mu g} / \boldsymbol{\mu} \mathbf{~ D P P H}\end{array}$ & $\begin{array}{c}\text { Antiradical } \\
\text { efficiency }\end{array}$ \\
\hline Methanol & $115.85 \pm 0.22$ & $24.64 \pm 0.05$ & 2.337 & 0.428 \\
Ethanol & $98.68 \pm 0.21$ & $18.22 \pm 0.04$ & 4.416 & 0.226 \\
Methanol: water (80:20) & $141.27 \pm 0.28$ & $36.24 \pm 0.10$ & 1.373 & 0.728 \\
Ethanol: water (50:50) & $118.61 \pm 0.34$ & $26.22 \pm 0.08$ & 1.733 & 0.577 \\
Ethyl acetate & $80.51 \pm 0.17$ & $9.04 \pm 0.02$ & 5.821 & 0.172 \\
Acetone & $66.92 \pm 0.13$ & $8.29 \pm 0.03$ & 8.052 & 0.124 \\
Water & $94.58 \pm 0.19$ & $19.50 \pm 0.07$ & 2.795 & 0.358 \\
\hline
\end{tabular}


Total flavonoids and flavonols content of olive pomace extracts

Total flavonoids and flavonols content of olive pomace extracts were determined to identify the quality and the structure of the OP phenolic compounds. Because of the antioxidant efficiency dose not correlate with the quantity of the phenolic compounds in all cases. The results are presented in Fig. 1. The results indicated that flavonoids and flavonols content were varied with the different extracts. Total flavonoid contents ranged from $12.52 \mathrm{mg} / \mathrm{g}^{-1}$ (DW) for methanol + water extract to $2.23 \mathrm{mg} / \mathrm{g}^{-1}$ (DW) for acetone extract. Regarding to the flavonols contents, methanol + water and ethanol+ water recorded the highest content with values of 6.73 and $5.72 \mathrm{mg} /$ $\mathrm{g}^{-1}$ (DW) respectively. On the other hand, aceton and ethyl acetate recorded the lowest flavonoids and flavonol contents of the olive pomace.

Identification of polyphenolic compounds from methanol: water extract of olive pomace

The phenolic compounds and derivatives of olive pomace methnolic extract in this study were fractionated an identified by HPLC/DAD. The protective chromatogram obtained at $290 \mathrm{~nm}$ along with the corresponding retention time, peaks number and beak relative area are presented in Fig. 2 and Table 3. The prime polyphenolic found in the studied extract are phenolic-acids, phenolic-alcohols, secoiridoid derivatives, and flavonoids. The major phenolic acids were galic, vanillic, caffeic and $\rho$ - coumaric acids. Caffeic acid showed the highest concentration, while galic acid and cinnamic acid recorded the lowest concentration in the methanolic pomace extract. Many factors were found to affect the phenolic compounds concentrations including the cultivar, agronomic, geographic origin of olive, olive tree irrigation, and technological conditions of oil production (Servili and Montendoro, 2002). These results agree with those reported by Vincenzo (2016) and Cioffi et al. (2010).

The chromatogram of olive pomace brings to light the presence of hydroxytyrosol and tyrosol as phenolic alcohols and oleuropein, ligstroside aglycone, and oleuropein aglycone as secoiridoid derivatives. Hdroxytyrosol have been revealed to be one of the most interesting phenolic compounds in the olive pomace, because of its strong antioxidant activity, anti-inflammatory and antimicrobial properties (Robles-Almazan, 2018). Moreover, this compound affects the quality properties (sensory and chemical) of food products was explored (Nunes et al., 20180). Oleuropein and oleuropein aglycone were found in olive oil and olive pomace (Fernendez-Bolanes et al., 2006, Goldsmith et al., 2014, Leouifoudi et al., 2014. and Sicari, 2016). Oleuropein also works as natural anti-oxidant in the body (Visioli et al., 2006). The results showed the presence Rutin and luteolin as flavonoids derivatives in the olive pomace. According to the literature data, these compounds were detected in olive oil and olive by-products (Dermeche et al., 2013).

Antioxidant activity of olive pomace extracts

Because of the undesirable effects of the synthetic antioxidants on human health and enzymes systems, the natural antioxidants can replace the synthetic one (Monica et al., 2007 and Baydar et al., 2007). The results of scavenging effects of the OP extracts are summarized in Fig. 3. It could be notice that inhibition ratio is increases by increasing the concentrations of extracts for all tested extracts. when low concentration $50 \mu \mathrm{g} / \mathrm{mL}$ was used, the remaining DPPH hanged from $93.63 \%$ for acetone extract to $60.38 \%$ for methanol+water extract. Meanwhile, when the concentration was increased to $300 \mu \mathrm{g} / \mathrm{mL}$ the remaining of DPPH was decreased to $64.72,8.38$, and $6.65 \%$ for acetone, ethanol +water, and methanol+water extracts respectively. These results may be due to the elevated polyphenolic content in methanol and ethanol extracts. Our findings are compatible with that stated by (Silva et al, 2006, Obied et al., 2007, and Leouifoudi et al., 2014).

The results in the same figure illustrate the scavenging activity of the OP extracts at different concentrations compared to the synthetic antioxidants (BHA, BHT, and BHTQ). Scavenging activity of OP was found to be concentration dependent. The results showed that methanol+water and ethanol+water had high scavenging activity as strong as BHA and BHT and recorded $\mathrm{EC}_{50}$ values of 1.373 and $1.728 \mu \mathrm{g} / \mu \mathrm{g}$ DPPH and antiradical efficiency values of 0.728 and 0.577 , respectively. The results also proved that acetone extract showed the lowest scavenging antioxidant activity with $\mathrm{EC}_{50}$ value of $8.052 \mu \mathrm{g} / \mu \mathrm{g}$ DPPH. The strong scavenging activity could be related to the high concentration of the antioxidant compounds in OP such as hydroxytyrosol, oleuropein, and oleuropein aglycon (Suarez et al., 2009 and Leouifoudi et al., 2014). 


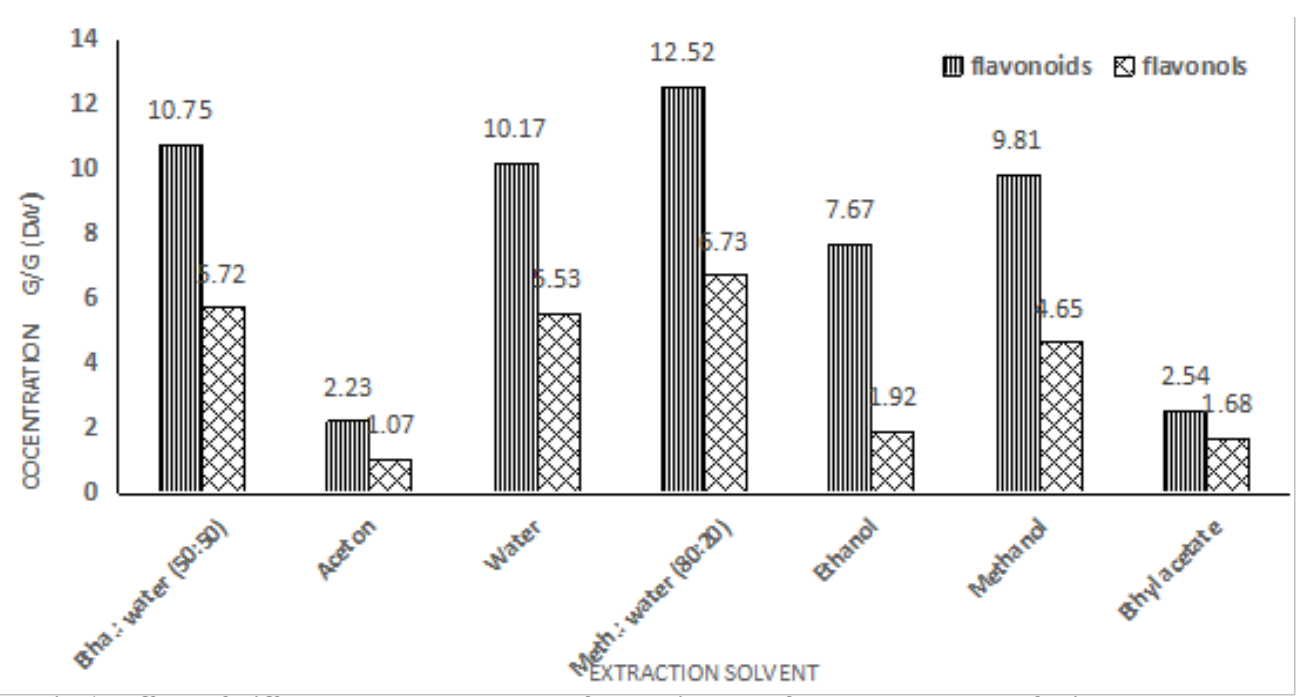

Fig.1. Effect of different solvents on total flavonoids and flavonols content of olive pomace.

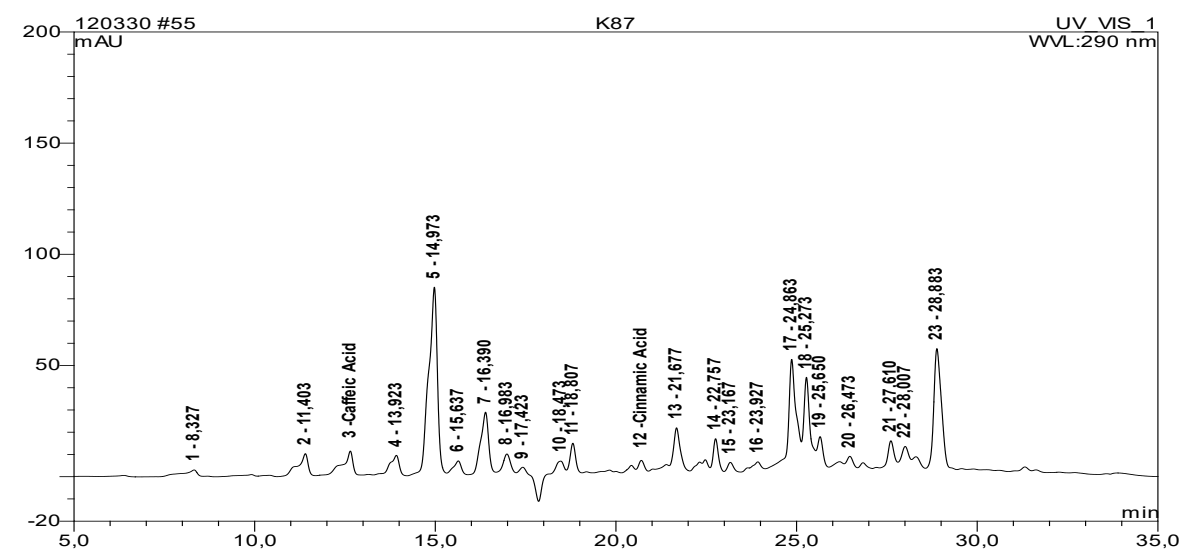

Fig.2. HPLC-DAD chromatogram of olive pomace methanolic extract.

TABLE 3. Phenolic components of olive pomace methanolic extract.

\begin{tabular}{|c|c|c|c|c|c|}
\hline No. & $\begin{array}{l}\text { R. T. } \\
\text { Min. }\end{array}$ & Peak Name & Height mAU & $\begin{array}{c}\text { Area } \\
\text { mAU*min }\end{array}$ & $\begin{array}{c}\text { Relative Area } \\
\% \\
\end{array}$ \\
\hline 1 & 8.33 & Gallic acid & 2.893 & 1.390 & 1.22 \\
\hline 2 & 11.4 & Hydroxytyrosol & 10.090 & 3.342 & 2.93 \\
\hline 3 & 12.65 & Caffeic acid & 10.873 & 3.706 & 3.25 \\
\hline 4 & 13.92 & Cumaric acid & 9.062 & 2.684 & 2.36 \\
\hline 5 & 14.97 & Tyrosol & 84.547 & 23.963 & 21.03 \\
\hline 6 & 15.64 & Vanillic acid & 6.272 & 1.652 & 1.45 \\
\hline 7 & 16.39 & Oleuropein & 27.784 & 7.064 & 6.20 \\
\hline 8 & 16.98 & NA & 8.605 & 1.999 & 1.75 \\
\hline 9 & 17.42 & Ligstroside aglycone & 6.360 & 2.967 & 2.60 \\
\hline 10 & 18.47 & NA & 14.712 & 8.113 & 7.12 \\
\hline 11 & 18.81 & oleuropein aglycone & 20.897 & 9.379 & 8.23 \\
\hline 12 & 20.7 & Cinnamic acid & 4.391 & 0.691 & 0.61 \\
\hline 13 & 21.68 & NA & 17.878 & 3.555 & 3.12 \\
\hline 14 & 22.76 & Ferulic acid & 13.727 & 2.074 & 1.82 \\
\hline 15 & 23.17 & NA & 4.207 & 0.748 & 0.66 \\
\hline 16 & 23.93 & NA & 2.932 & 0.552 & 0.48 \\
\hline 17 & 24.86 & Oleuropein glucoside & 48.869 & 12.416 & 10.90 \\
\hline 18 & 25.27 & Luteolin & 40.621 & 8.189 & 7.19 \\
\hline 19 & 25.65 & Luteolin-7-glucoside & 13.812 & 2.484 & 2.18 \\
\hline 20 & 26.61 & $\mathrm{NA}$ & 4.130 & 0.688 & 0.60 \\
\hline 21 & 27.61 & Rutin & 10.918 & 1.886 & 1.65 \\
\hline 22 & 28.01 & NA & 6.671 & 1.217 & 1.07 \\
\hline 23 & 28.88 & NA & 53.992 & 13.190 & 11.58 \\
\hline
\end{tabular}




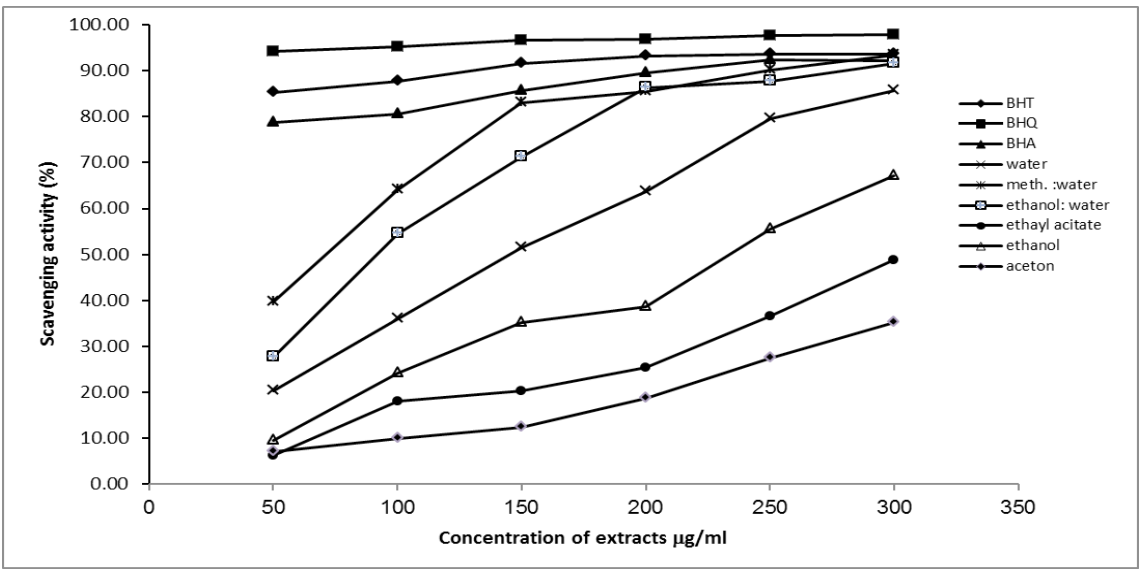

Fig. 3. Scavenging activity of olive pomace at assorted concentration against DPPH radical and comparing with synthetic antioxidants .

Sensory evaluation of toast bread samples fortified with olive pomace cellulose

Cellulose is one of the main olive cell wall polysaccharides recovered from olive pomace (Catanakis et al., 2010). In food industry, the valorization of native dietary fibers appears to be to be interesting fields, it is now well-known to have role in prevention of several diseases such as cancer (Rodríguez et al., 2006). There are less publications on the utilization of olive pomace in foods especially its effects on the rheological properties of the dough when used as a substitute for wheat flour in bread making. In this part of the study, isolated cellulose from olive pomace was used in fortification of toast bread and its effects on the rheological and sensory properties of the bread was investigated.Results of sensory evaluation of produced bread with different added levels of OP cellulose are given in Table 4. It indicated no significant differences between the control and the sample fortified by $2 \%$ cellulose in all the tested parameters. The results showed that increasing the fortification ratio to $4 \%$ led to no significant differences $(\mathrm{p}<0.05)$ between the control and the sample in color, taste and texture and significant differences in, odour, appearance and overall acceptability.

The bread with 2\% substitution level was superior in all sensory characteristics evaluated compared to other replacement ratios. Moreover, it recorded higher scores in texture, appearance and overall acceptability than the control sample. When $6 \%$ of the flour were replaced with cellulose,significant drops in the values of all the sensory characteristics were observed in the resulting bread. Our results are similar to that presented by Cecchi, et al. (2019) for pasta, bread, and granola bar fortified with olive pomace. Cedola et al. (2019) found that addition of dry olive paste flour to the bread also slightly interfered with the network formation, thus influencing the final bread bubbles that were considered more acceptable in the control samples than in the enriched bread. The Sensory evaluation of cellulose-enriched baked rolls indicated that addition of cellulose by up to $1 \%$ was identical to the control rolls. It was also found that increasing the addition levels of cellulose significantly reduced the crus, taste, porosity and color of the produced rolls (Lauková et al. (2017). Likewise, Gómez et al. (2003) mentioned that it is possible to add dietary fibers to the flour while making bread by up to $2 \%$ without. Ang and Miller (1989) used cellulose powder in the cake manufacture with different addition ratios and measured the texture of the cake. They found that the low levels of cellulose addition led to the cake being produced more harder texture than those with a high level of cellulose. This can be because long fibers contribute to a soft cake. They also noticed that these ratios from adding up to $4 \%$ improve the overall appearance and reduce moisture loss from the surface cracking as well as extending the shelf life of the cake (Kamel and Stauffeer, 1993 and Prakongpan et al, 2002).

\section{Quality characteristics of toast bread}

Regarding to the effect of adding cellulose in the bread formula in the chemical composition of the produced bread, the results in Table 5 showed that moisture content of the bead was increased with increasing the fortification level. There were no significant differences between 
the control sample and the sample fortified with $2 \%$ olive cellulose. As prospective, it was noted that the bread samples to which cellulose was added contained higher fibers than those made without adding cellulose. Besides, the results also demonstrated no significantly differences among the control and the bread samples with $2 \%$ and $4 \%$ added olive cellulose powder in protein, lipid and ash contents. Our results were similar to that obtained by Lin et al. (2017). For olive pomace based high fiber biscuit. Sodchit et al. (2013) added banana peel cellulose powder to butter cake at three levels and found that addition cellulose to the cake improved the fiber content of the product. They also observed that sample with $1.5 \%$ added cellulose recorded no significant differences compared with the control in protein, moisture, total lipid and ash contents.

Effect of addition of olive pomace cellulose on the rheological properties of the dough

\section{Farinograph characteristics}

It was found that adding dietary fibers to the bread improves the nutritional value, but at the same time it may lead to a change in some of the rheological properties of the dough, and this may lead to an effect on the quality of the bread and the sensory properties of bread (Rosell et al., 2005). Farinographic properties of doughs with several levels of olive pomace cellulose are given in Table (6). Water is an important component of baking dough because it takes part in hydration of gluten, thus ensuring that the dough maintained carbon dioxide. Also, the ability of dough to absorb water (WA) is of great importance in bread industry. The water absorption of dough with $2 \%$ olive pomace cellulose substitution was $54.5 \%$ and it is higher than that of control dough. When the olive

\section{Extensograph properties}

According to the results of extensographic properties of doughs with added olive pomace cellulose (Table 6), the controls sample recorded the highest extensibility while the sample substituted with $6 \%$ cellulose showed the lowest extensibility value. Thus, it can be observed that addition of olive pomace cellulose caused the extensibility of the dough samples to decrease. Similar findings were reported by Koca and Anil (2007) for replacement of wheat flour with flaxseed flour in bread. Likewise, Poran et al. (2008) found that addition of cellulose to the wheat flour reduced the extensibility of dough. This finding could be attributed to the protein content decreases when flour is substituted by powdered cellulose and as a result, the dough loses portion of its expandability property. A consequence, the dough loses part of its extensibility property. Also, the dough demand for water increased when fibre was added and these led to dilution of gluten and reduce extensibility of the dough. The resistances to extension of dough samples are presented in Table 6. The results indicated that there was a highly significant increase in the resistance of dough, when the flour was substituted with powdered cellulose. The resistance of the dough increased from for the control to for $6 \%$ cellulose flour sample. Such increment in the resistance could be due to the interaction between the olive cellulose and gluten in wheat flour. Many studies declared negative effect of adding insoluble fiber on the formation of gluten network (Pourabedin et al., 2017, and Ahmed et al., 2013). The energy value of dough with $2 \%$ olive pomace cellulose substitution was analogous to the control. However, the energy values of doughs made with $4 \%$ and $6 \%$ olive pomace cellulose were significantly lower than that of control dough.

TABLE 4. Sensory evaluation of toast bread fortified with olive pomace cellulose.

\begin{tabular}{|c|c|c|c|c|c|c|}
\hline \multirow[b]{2}{*}{ Samples } & \multicolumn{6}{|c|}{ Sensory characteristics } \\
\hline & Color & Taste & Odour & Texture & Appearance & $\begin{array}{c}\text { Overall } \\
\text { acceptability }\end{array}$ \\
\hline Control & $9.20 \pm 0.15^{\mathrm{a}}$ & $9.23 \pm 0.37^{\mathrm{a}}$ & $9.04 \pm 0.34^{\mathrm{a}}$ & $8.20 \pm 0.39^{\mathrm{ab}}$ & $9.11 \pm 0.22^{\mathrm{a}}$ & $8.23 \pm 0.27^{\mathrm{a}}$ \\
\hline $2 \% \mathrm{OPC}^{*}$ & $8.8 \pm 0.38^{\mathrm{a}}$ & $8.92 \pm 0.54^{\mathrm{a}}$ & $8.91 \pm 0.12^{\mathrm{a}}$ & $8.90 \pm 0.18^{\mathrm{a}}$ & $8.95 \pm 0.32^{\mathrm{a}}$ & $8.53 \pm 0.44^{\mathrm{a}}$ \\
\hline $4 \%$ OPC & $8.75 \pm 0.29^{\mathrm{a}}$ & $8.85 \pm 0.42^{\mathrm{a}}$ & $8.17 \pm 0.19^{b}$ & $8.10 \pm 0.32^{\mathrm{b}}$ & $8.38 \pm 0.17^{b}$ & $8.16 \pm 0.14^{b}$ \\
\hline $6 \%$ OPC & $7.94 \pm 0.41^{\mathrm{b}}$ & $6.81 \pm 0.22^{\mathrm{b}}$ & $6.90 \pm 0.71^{\mathrm{c}}$ & $7.43 \pm 0.54^{\mathrm{c}}$ & $6.82 \pm 0.27^{\mathrm{c}}$ & $7.14 \pm 0.19^{c}$ \\
\hline
\end{tabular}

$\mathrm{OPC}=$ olive pomace cellulose 
TABLE 5. Chemical composition of toast bread fortified with 2,4 and $6 \%$ olive pomace cellulose.

\begin{tabular}{ccccccc}
\hline \multirow{2}{*}{ Samples } & \multicolumn{5}{c}{ Chemical composition (\%) } \\
\cline { 2 - 7 } & Moisture & Protein & Ash & Total lipids & Fiber & Carbohydrates \\
\hline Control & $11.20 \pm 0.23^{\mathrm{b}}$ & $10.95 \pm 0.33^{\mathrm{b}}$ & $1.79 \pm 0.14^{\mathrm{a}}$ & $3.80 \pm 0.43^{\mathrm{a}}$ & $3.22 \pm 0.32^{\mathrm{d}}$ & $80.66 \pm 1.40^{\mathrm{a}}$ \\
$\mathbf{2} \%$ OPC & $11.44 \pm 0.40^{\mathrm{b}}$ & $10.71 \pm 0.27^{\mathrm{b}}$ & $1.78 \pm 0.19^{\mathrm{a}}$ & $3.79 \pm 0.23^{\mathrm{a}}$ & $3.90 \pm 0.41^{\mathrm{c}}$ & $79.92 \pm 1.55^{\mathrm{a}}$ \\
$\mathbf{4} \%$ OPC & $11.98 \pm 0.64^{\mathrm{a}}$ & $10.22 \pm 0.29^{\mathrm{ab}}$ & $1.77 \pm 0.09^{\mathrm{a}}$ & $3.78 \pm 0.28^{\mathrm{a}}$ & $4.38 \pm 0.50^{\mathrm{b}}$ & $79.55 \pm 1.70^{\mathrm{a}}$ \\
$\mathbf{6 \%}$ \%PC & $12.09 \pm 0.92^{\mathrm{a}}$ & $9.69 \pm 0.74^{\mathrm{a}}$ & $1.75 \pm 0.11^{\mathrm{a}}$ & $3.76 \pm 0.33^{\mathrm{a}}$ & $5.14 \pm 0.40^{\mathrm{a}}$ & $79.26 \pm 1.60^{\mathrm{a}}$ \\
\hline
\end{tabular}

$\mathrm{OPC}=$ olive pomace cellulose

TABLE 6. Effect of olive pomace cellulose addition on Farinogragh and Extensograph parameters of wheat flour (82\% extraction).

\begin{tabular}{|c|c|c|c|c|c|}
\hline & \multicolumn{5}{|c|}{ Farinogragh parameters } \\
\hline $\begin{array}{l}\text { parameters } \\
\text { Samples }\end{array}$ & $\begin{array}{c}\text { Water absorption } \\
\% \\
\end{array}$ & Arrival time (min) & $\begin{array}{c}\text { Developing } \\
\text { time (min) }\end{array}$ & $\begin{array}{c}\text { Stability time } \\
(\mathrm{min})\end{array}$ & $\begin{array}{l}\text { Weakening } \\
\text { value (BU) }\end{array}$ \\
\hline Control & $53.6^{\mathrm{c}}$ & $0.5^{\mathrm{c}}$ & $1.0^{\mathrm{c}}$ & $4.50^{\mathrm{a}}$ & $70^{\mathrm{c}}$ \\
\hline $2 \%$ & $54.5^{\mathrm{b}}$ & $1.5^{\mathrm{b}}$ & $2.0^{\mathrm{b}}$ & $3.52^{\mathrm{b}}$ & $80^{\mathrm{b}}$ \\
\hline $4 \%$ & $56.9^{\mathrm{b}}$ & $1.5^{\mathrm{b}}$ & $2.25^{\mathrm{b}}$ & $3.51^{\mathrm{b}}$ & $80.5^{\mathrm{b}}$ \\
\hline $6 \%$ & $66.8^{\mathrm{a}}$ & $2.2^{\mathrm{a}}$ & $3.1^{\mathrm{a}}$ & $3.04^{\mathrm{c}}$ & $90.7^{\mathrm{a}}$ \\
\hline \multicolumn{6}{|c|}{ Extensograph parameters } \\
\hline & Extensibility (mm) & Resistance (BU) & proportional & aber & Energy $\left(\mathrm{cm}^{2}\right)$ \\
\hline Control & 125 & 445 & 3.65 & & 63 \\
\hline $2 \%$ & 110 & 462 & 4.21 & & 58 \\
\hline $4 \%$ & 101 & 468 & 4.63 & & 48 \\
\hline $6 \%$ & 95 & 484 & 5.09 & & 40 \\
\hline
\end{tabular}

\section{Conclusion}

This research confirmed that the quantity of polyphenolic compoundst in the olive pomace were ranged between 36.24 to $8.29 \mathrm{mg} / \mathrm{g}^{-1} \mathrm{DW}$ depending on the extraction solvent used. The major polyphenolic compounds in the olive pomace were tyrosol, hydroxytyrosol, oleuropein, and oleuropein aglycon, luteolin and rutin. The results showed that olive pomace methanolic extracts had high scavenging activity as strong as BHA and BHT which could be related to the high concentration of the antioxidant compounds in OP such as hydroxytyrosol, oleuropein, and oleuropein aglycon. Adding olive pomace cellulose powder to wheat flour led to significant alters in farinograph parameters. Addition of $2 \%$ cellulose powder enhanced the texture and the acceptability of the toast bread compared with the control sample, . It can be concluded that

Egypt. J. Food Sci. 48, No.1 (2020) olive pomace cellulose could be used as wheat replacer in toast making at the level of $2 \%$ with no impairment on quality characteristics of the bread.

\section{Acknowledgment}

This study was financial propped by Cultural Affairs and Missions Sector, Egypt and University of Applied Science Weihenstephan-Triesdorf, Weidenbach, Germany.

\section{$\underline{\text { Referances }}$}

AACC. (1983) Approved methods of the AACC. (Method 54-10). $8^{\text {th }}$ ed. American Association of Cereal Chemists, The Association, Saint Paul, Minnesota, U.S.A.

Ahmed, J., Almusallam, A.S., Al-Salman, F., AbdulRahman, M.H., Al-Salem, E., (2013) Rheological properties of water insoluble date fiber incorporated wheat flour dough. LWT - Food Sci. Technol. 51, 409-416 
Alburquerque, J.A., Gonzalvez, J., Garcia, D., and Cegarra, J. (2004) Agrochemical characterisation of "alperujo", a solid byproduct of the two-phase centrifugation method for olive oil extraction. Bioresource Technology, 91, 195-200.

Alu'datt, M. H., Alli, I., Ereifej, K., Alhamad, M., Al-Tawaha, A. R., and Rababah, T. (2010) Optimisation, characterization and quantification of phenolic compounds in olive cake. Food Chemistry, 123, 117-122

Ang, J. F. and Miller, W. B. (1989) Enhancement of cake volume by a new form of powdered cellulose. Abstract AACC Annual Meeting. 74 (3), 162

AOAC, (2012) Official Methods of Analysis. Association of Analytical Communities, USA.

Araújo, M., Pimentel, B. F., Alves, R. C., and Oliveira, B.P. (2015). Phenolic compounds from olive mill wastes: Health effects, analytical approach and application as food antioxidants. Trends in Food Science \& Technology, 45, 200-211.

Baydar, N. G., Ozkan G., and Yasser, S. (2007) Evaluation of the antiradical and antioxidant potential of grape extracts. Food Control, 18, 11311136.

Brand-Williams, W.; Culivier, M. E, and Berset, C. (1995) Use of free radical method to evaluate antioxidant activity. LWT- Food Science and Technology, 28 (1), 25-30.

Brendel, O., Iannetta, P. M. and Stewart, D. (2000) A rapid and simple method to isolate pure $\alpha$-cellulose. Phytochemical Analysis, 11, 7-10.

Cecchi, L., Schuster, N., Flynn, D., Bechtel, R., Bellumori, M., Innocenti, M., Mulinacci, N., and Guinard, J-X. (2019) Sensory profiling and consumer acceptance of pasta, bread, and granola bar fortified with dried olive pomace (Pat^e): A byproduct from virgin 'olive oil production. Journal of Food Science, 84, (10), pp. 2995-3008.

Cedola1, A., Cardinali, A., Del Nobile, M. A. and Conte, A. (2019) Enrichment of Bread with Olive Oil Industrial By-Product. Journal of Agricultural Science and Technology, B 9, 119-127

Chanioti, S., and Tzia, C. (2017) Optimization of ultrasound-assisted extraction of oil from olive pomace using response surface technology: oil recovery, unsaponifiable matter, total phenol content and antioxidant activity. LWT Food Sci. Technol., 79, 178-189.
Chen, H.; Rubenthaler, G. L. and Schanus, E. G. (1988) Effect of apple fiber and cellulose on physical properties of wheat flour. Journal of Food. Science, 53, 304-305.

Cioffi, G., Pesca, M. S., De Caprariis, P., Braca, A., Severino, L., and De Tommasi, N. (2010) Phenolic compounds in olive oil and olive pomace from Cilento (Cam-pania, Italy) and their antioxidant activity. Food Chemistry, 121, 105-111.

Contrerno, L., Martinelli, F., Tamburini, M., Fava, F., Mancini, A., Sordo, M., Pindo, M., Martens, S., Masiero, D., Vrhovsek, U., Dal Lago, C., Ferrario, G., Morandini, M. and Tuohy K. (2017) Measuring the impact of olive pomace enriched biscuits on the gut microbiota and its metabolic activity in mildly hypercholesterolaemic subject. Ers. J. Nutr. 15721591

De Marco, E., Savarese, M., Paduano, A., and Sacchi, R. (2007) Characterization and fractionation of phenolic compounds extracted from olive oil mill wastewaters. Food Chemistry, 104, 858- 867.

Dermeche, S., Nadoura, M., Larroche, C., MoultiMati, F., and Michaud, P. (2013) Olive mill wastes: biochemical characterizations and valorization strategies. Process Biochemistry, 48 (10), 15321552

Di Gioiam, D., Barberio, C., and Spagnesi S. (2002) Characterization of four olive-mill-wastewater indigenous bacterial strains capable of aerobically degrading hydroxylated and methoxylated monocyclic aromatic compounds. Arch Microbiology, 178, 208-217.

Di Giovacchino, L., Prezioso, S. (2006) Utilization of olive mill by-products. In: Proceedings of "Olive .bioteq Recent advances in olive industry, 379-89.

Fahmi, R. (1984) Chemical investigation of some different varieties of soybean grown in Egypt. Ph.D. Thesis, Biochemistry Dept. Fac. of Science, Cairo, Univ. Egypt.

Fernández-Bolaños, J., Rodríguez, G., Rodríguez, R., Guillén, R. and Jiménez, A. (2006) Extraction of interesting organic compounds from olive oil waste. Grasasy Aceites, 57 (1), 95-106.

Galanakis, CM., Tornberg, E., and Gekas, V. (2010) A study of the recovery of the dietary fibres from olive mill wastewater and the gelling ability of the soluble fiber fraction. LWT- Food Sci Technol.; 43:1009-17. 
Ghanbari, R., Anwar, F., Alkharfy, K. M., Gilani, A-H., and Saari, N.(2012) Valuable Nutrients and Functional Bioactives in Different Parts of Olive (Olea europaea L.)-A Review, Int. J. Mol. Sci.; 13, (3): 3291-3340

Ghelof, N., Engeseth, N J., and Wang, X-H. (2002) Identification and Quantification of Antioxidant Components of Honeys from Various Floral Sources. Journal of Agricultural and Food Chemistry, 50, (21), 5870-7

Goldsmith, C.D., Stathopoulos, C. E., Golding, J. B. and Roach, P. D. (2014) Fate of the phenolic compounds during olive oil production with the traditional press method. International Food Research Journal, 21(1), 101-109.

Gómez, M.; Ronda, F., Blanco, C. A., Caballer, P. A.and Apesteguía, A. (2003) Effect of dietary fibre on dough rheology and bread quality. Eur. Food Res. Technol., 216, 51-56

Gordon, M., Paiva-Martins, F., Almeida, M., (2001) Antioxidant activity of hydroxytyrosol acetate with that of other olive oil polyphenols. J. Agric. Food Chem. 49, 2480-2485.

Hruškova, M. and Svec, I. (2017) Rheological characteristics of composite flour with linseed fiber-relationship to bread quality. Czech J. Food Sci., 35, (5): 424-431.

Jerman Klen, T., and Mozetic Vodopivec, B. (2012) The fate of olive fruit phenols during commercial olive oil processing: traditional press versus continuous two- and three-phase centrifuge. $L W T$. Food Science and Technology, 49, 267-274.

Jiménez, A, Guillén, R, Fernández-Bolanos, J. and Heredia, A. (1994) Cell wall composition of olives. J. Food Sci., 59, 1192-6.

Kamel, B. S. and Stauffer, C. (1993) Advances in Baking Technology. $1^{\text {st }}$ ed., VCH Publisher, New York, U.S.A

Charis M. Galanakis, M. C. (2011) Olive fruit dietaryfiber: components, recovery and applications. Trends in Food Science \& Technology, 22 (2011) $175 \mathrm{e} 184$

Lafka, T-I., Lazou, A. E., Sinanoglou, V. J., and Lazos, E. S. (2011) Phenolic and anti-oxidant potential of olive oil mill wastes. Food Chemistry, 125 (1), 9298.

Lauková, M., Kohajdová, Z., Karovičová, J., Kuchtová, V., Minarovičová, L., and Tomášiková, L. (2017)
Effects of cellulose fiber with different fiber length on rheological properties of wheat dough and quality of baked rolls. Food Sci. Technol. Int., 23 (6), 490-499.

Leouifoudi, I., Zyad, A., Amechrouq, A., Oukerrou, M.A., Mouse, H.A., and Mbarki, M. (2014) Identification and characterization of phenolic compounds extracted from Moroccan olive mill wastewater. Food science and technology, 34 (2), 294-257.

Lin, S., Chi, W., Hu, J., Pan, Q., Zheng, B. Zeng, S. (2017) Sensory and nutritional properties of chinese olive pomace based high fibre biscuit. Emirates Journal of Food and Agriculture. 29 (7): 495-501

Meilgaard, M.C., Civileand, G.V. and Carr, B.T. (2007) Sensory Evaluation Techniques. $4^{\text {th }}$ ed. CRC Press: New York

Mohdaly, A., Sarhan, M., Smetanska, E., and Mahmoud, A. (2009) Antioxidant properties of various solvent extracts of potato peel, sugar beet pulp and sesame cake. Journal of Food Science and Agriculture, 90: 218-226.

Monica, D., Anthon, R., Guilia, C., Amaela, A., Alessandra, L., Francesco, V., Paoa, M., and Assunta, M. (2007) Protective effect of olive oil minor polar compounds against oxidative damage in rats treated with ferric nitrilotriaceate. Food Chemical Toxicology, 45, 233-240.

Niaounakis M, and Halvadakis P. (2004) Olivemill waste management: literature review and patent survey, $1^{\text {st }}$ ed, Typothito-George Dardanos Publications, Athens

Nunes, M. A., Costa, A. S., Bessada, S., Santos, J., Puga, H., Alves, R. C., Freitas, V., and Oliveira, M. B., (2018) Olive pomace as a valuable source of bioactive compounds: A study regarding its lipidand water-soluble components. Science of The Total Environment, 644, 229-236

Obied, H. K., Bedgood, D. R., Prenzler, P. D., and Robards, K. (2007) Bioscreening of Australian olive mill waste extracts: Biophenol content, antioxidant, antimicrobial and molluscicidal activities. Food and Chemical Toxicology, 45 (7), 1238-1248.

Obied, H. K., Prenzler, P. D., Ryan, D., Servili, M., Taticchi, A., and Esposto, S., (2008) Biosynthesis and biotransformation's of phenol-conjugated oleosidic secoir-idoids from Olea europaea L. Natural Product Reports, 25, 1167-1179.

Egypt. J. Food Sci. 48, No.1 (2020) 
Paz Aguilera, M. eltran, G., Ortega, D., Fernandez, A., Jimenrz, A., and Uceda, M. (2005) Characterization of virgin olive oil of Italian olive cultivars: Frantoio and Leccino grown in andalusia. Food Chemistry, 89, 387-391.

Poran, S., Goburdhun, D., Ruggoo, A. (2008) Effects of adding cellulose on rheological characteristics of wheat flour dough and on bread quality. University of Mauritius Research Journal, 14, 112-128.

Portarena, S., Baldacchini, C., and Brugnoli, E. (2017) Geographical discrimination of extra-virgin olive oils from the Italian coasts by combining stable isotope data and caroten-oid content within a multivariate analysis. Food Chemistry, 215, 1-6.

Pourabedin, M., Aarabi, A. and Rahbaran, S. (2017). effect of flaxseed flour on rheological properties, staling and total phenol of Iranian toast. J. Cereal Science, (76), 173-178

Prakongpan, T. Nitithamyong, A. and Luanpituksa, P. (2002) Extraction and application of dietary fiber and cellulose from pineapple cores. Journal of Food Science, 67 (4), 1308-1313.

Robles-Almazan, M., Pulido-Moran, M., MorenoFernandez, J., Ramirez-Tortosa, C., RodriguezGarcia, C., Quiles, J. L., Ramirez-Tortosa, M.C., (2018) Hydroxytyrosol: bioavailability, toxicity, and clinical applications. Food Res. Int., 105, 654667.

Rodrigues, F., Nunes, M.A., and Oliveira, M.B.P., (2017) Applications of recovered bioactive compounds in cosmetics and health care products. In: Galanakis, C.M. (Ed.), Olive Mill Waste - Recent Advances for Sustainable Management. Academic Press, pp. 255-274.

Rodríguez, R., Jiménez A., Fernández-Bolaños, J., Guillén, R., and Heredia, A. (2006) Dietary fibre from vegetable products as source of functional ingredients. Trends Food Sci. Technol., 17 (1), $3-15$.

Roig, A., Cayuela, M., and Sanchez-Monedero, M. (2006) An overview on live mill wastes and their valorization methods. Waste Management, 26, 960-969.

Rosell, CM., Santos, E., and Collar, C. (2005) Mixing properties of fiber-enriched wheat bread doughs: A response surface methodology study. Eur. Food Research and Technology, 223, (3), 323-340.

Roselló-Soto, E., Koubaa, M., Moubarik, A., Lopes, R.P., Saraiva, J.A., Boussetta, N., Grimi, N., and
Barba, F.J. (2015) Emerging opportunities for the effective valorization of wastes and by-products generated during olive oil production process: non-conventional methods for the recovery of high-added value compounds. Trends Food Sci. Technol., 45, 296-310.

Rubio-Senent, F., Rodriguez-Gutierrez, G., LamaMunoz, A., and Fernandez-Bolanos, J. (2012) New phenolic compounds hydrothermally extracted from the olive oil byproduct alperujo and their antioxidative activities. Journal of Agricultural and Food Chemistry, 60, 1175- 1186.

Servili, M., \& Montedoro, G. (2002) Contribution of phenolic compounds to virgin olive oil quality. European Journal of Lipid Science and Technology, 104, 602-613.1

Sicari, V. (2017) Antioxidant potential of extra virgin olive oils extracted from three different varieties cultivated in the Italian province of Reggio Calabria. Journal of Applied Botany and Food Quality, 90, 76 - 82.

Silva, S., Gomes, L., Leitão, F., Coelho, A. V., and Vilas Boas, L. (2006) Phenolic compounds and antioxidant activity of Oleaeuropaea L. fruit and leaves. Food Science and Technology International, 12 (5), 385- 396.

Singanusong, R., Tochampa, W., Kongbangkerd, T. and Sodchit, C, (2014) Extraction and properties of cellulose from banana peels. Suranaree J. Sci. Technol. 21 (3), 201-213.

Sodchit, C., Tochampa, W., Kongbangkerd, T. and Singanusong, R. (2013) Effect of banana peel cellulose as a dietary fiber supplement on baking and sensory qualities of butter cake. Songklanakarin J. Sci. Technol. 35 (6), 641-646, 2013

Suarez, M., Romero, M.-P., Ramo, T., Macia, A., and Motilva, M.-J. (2009) Methods for preparing phenolic extracts from olive cake for potential application as food antioxidants. Journal of Agricultural and Food Chemistry, 57, 1463-1472.

Vergani, L., Vecchinoe, G., Baldini, F., Voci, A., Ferrari, F., Aliakbarian, B., Casazza, A., and Perego, P. (2016) Antioxidant and hepatoprotective potential of phenolic compounds from olive pomace. Chemical Engineering Tansactions, Vol. 49, 475- 840 .

Visioli, F., Poli, A., and Galli, C. (2002) Antioxidant and other biological activities of phenols from

Egypt. J. Food Sci. 48, No.1 (2020) 
olives and olive oil. Medicinal Research Reviews, 22 (1), 65-75.

Vlyssides, AG., Loizidou, M., Gimouhopoulos, K., and Zorpas, A. (1998) Olive oil processing wastes production and their characteristics in relation to olive oil extraction methods. Fresen Environ Bull. 7, (5-6):308-13.

Wang, M., Hamer, R.J., Van Vliet, T., Gruppen, H., Marseille, H., Weegels, P.L. (2003) Effect of water unextractable solids on gluten formation and properties: mechanistic considerations. J. Cereal Sci., 37, 55-64.
Winkelhausen, E., Pospiech, R. and Laufenberg, G. (2005) Antifungal activity of phenolic compounds extracted from dried olive pomace. Bulletin of the Chemists and Technology of Macedonia, Vol.24, (1): 41-46.

Wongsonsarim, C., Kowattanakul, T. and Donyasak, B. (2001) Using cellulose powder from soybean shell and greenbean shell in deep-fried dough stick. Bangkok, Thailand: Chulalongkorn University, Special problems.

الاستفادة من كسب الزيتون كمصدر للمركبات النشطة في تحسين جودة الخبز المحمص

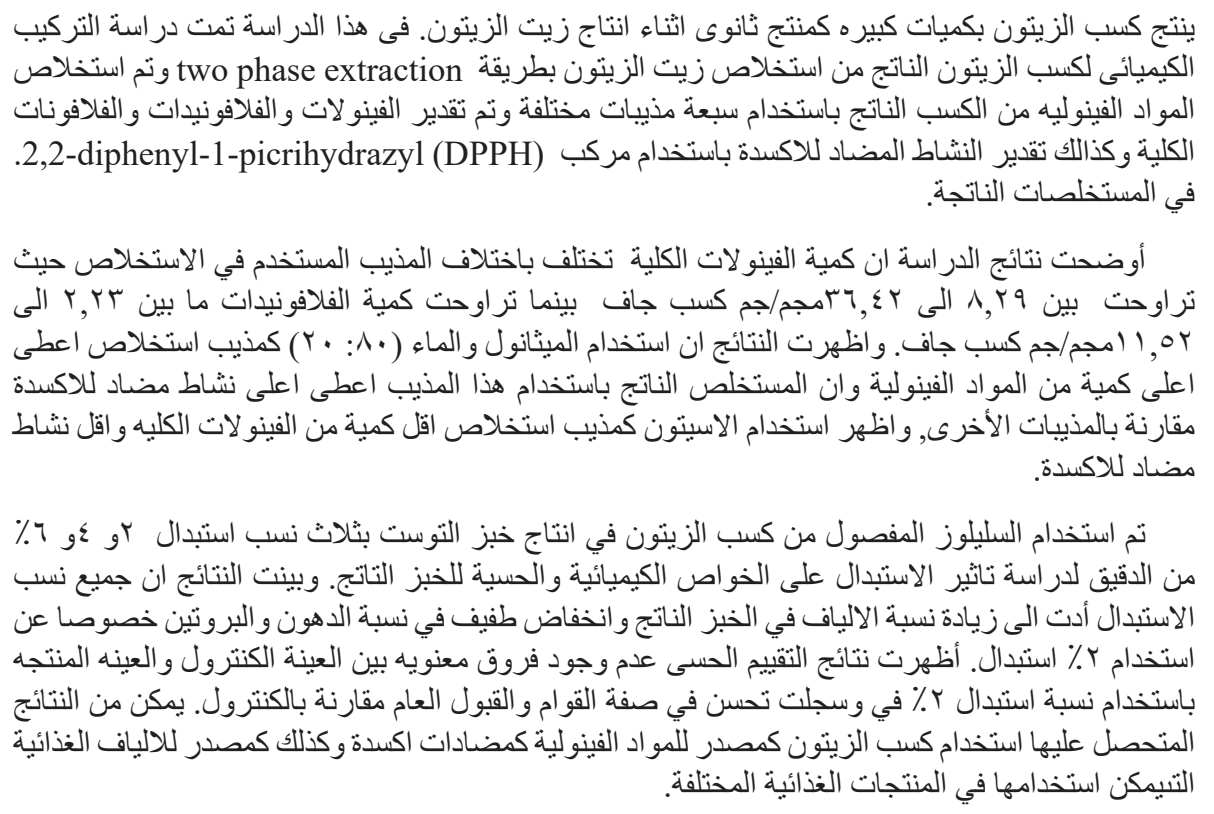

